\title{
Doença do enxerto contra hospedeiro pós-transfusional-guia para irradiação gama de hemocomponentes
}

\author{
E.P. LANDI, J .S.R. DE OLIVEIRA
}

Trabal ho desenvol vido no Departamento de Hematologia eH emoterapia da Casa de Saúde Santa Marcelina, Hospital E val do F oz e pela Disciplina de Hematologia da Universidade Federal de São Paulo/E PM, São Paulo, SP.

RESUMO - A doença enxerto contra hospedeiro transfusional (DECHT) é síndrome rara e geralmente fatal. É caracterizada por febre, eritema cutâneo, náuseas, vômitos, diarréia, hepatite e pancitopenia. Pode ocorrer em pacientes com imunossupressão severa e em pacientes imunocompetentes após a transfusão de hemocomponente celular de doador homozigoto para proteínas HLA às quais o receptor é heterozigoto. 0 diagnóstico é feito pelo quadro clínico e exame histopatológico da pele. A gamaglobulina antitimocítica associada a altas doses de corticosteróides é a terapêutica mais empregada. O desconhecimento da síndrome, o retardo no diagnóstico, o curso rápi do e a ausência de resposta ao tratamento estão relacionados à má evolução dos pacientes. A melhor forma de abordagem da DECHT é a prevenção através da irradiação gama dos hemocomponentes. A dose necessária para completa inativação dos linfócitos T é de 2500 cGy. A principal alteração decorrente da irradiação é o aumento da concentração de potassio nos concentrados de hemácias.

\section{INTRODUÇAO}

A identidade imunológica de um indivíduo é expressa por um conjunto de proteínas de superfície cel ular denominadas de complexo de histocompatibilidade (CHP). O complexo de histocompatibilidade principal, também denominado de antígenos leucocitários humanos (HLA), juntamente com o complexo de histocompatibilidade secundário, estão diretamente relacionados à resposta imunológica garantindo a manutenção da integridade dos tecidos. Quando um organismo é exposto a antígenos estranhos, ocorre interação entre as proteínas do sistema HLA das células apresentadoras de antígenos (CAA) e este antígeno. O produto desta interação permite o reconhecimento do antígeno pelos linfócitos T, CD4 ou CD8, e conseqüente ativação e produção de mediadores celulares capazes de iniciar toda resposta imunológicaํ.

Quando linfócitos T maduros, histoincompatíveis e viáveis são transplantados a um organismo inca-
Os filtros de leucócitos não previnem o desenvolvimento da DECHT e a irradiação não previne a aloi munizaçao e as reaçoes transfusionais. Apenas hemocomponentes celulares como sangue total, concentrado de hemácias, concentrado de plaquetas e concentrado de granulócitos, necessitam ser irradiados. Devem ser irradiados os hemocomponentes para transfusão entre familiares, transfusões HLA compatíveis, pacientes submetidos a transplante de medula óssea, portadores de doença de Hodgkin, pacientes tratados com análogos da purina, transfusões intra-útero, recém nascidos pré-termo e pacientes com síndrome de imunodeficiência congênita. É recomendável a irradiação de hemocomponentes destinados a pacientes com doenças neoplásicas quando submetidos a protocolos de quimioterapia agressivos.

UNITERMOS: Doença enxerto contra hospedeiro. I munodeficiência. Transfusão de hemocomponentes e irradiação gama.

paz de reconhecê-los como estranhos, estes são diretamente estimulados pelas proteínas H LA do hospedeiro. As condições para ativação, replicação e ação desses linfócitos são promovi das pelo próprio hospedeiro e contra ele destinado². A manifestação clínica desta condição é chamada de doença enxerto contra hospedeiro (DECH).

A DECH é uma síndrome clínica caracterizada por febre, acometimento cutâneo, anorexia, náuseas, vômitos, diarréia e disfunção hepática. É comumente observada nos transplantes de medula óssea (TMO) alogênicos, histocompatíveis, por diferenças nos antígenos de histocompatibilidade secundários. Pode também ocorrer noTMO singênico ${ }^{3}$, autól ogo ${ }^{4,5}$, transplantes de órgãos sólidos que contenham grande quanti dade de tecido linfóide $e^{6,7}$ e em transfusão de hemocomponentes (Tab.1).

A manifestação de DECH após a transfusão de hemocomponentes é conhecida como doença enxerto contra hospedeiro transfusional (DECHT). Difere da primeira por cursar com pancitopenia 
secundária a hipoplasia ou aplasia de medula óssea, baixa resposta ao tratamento e el evada mortalidade. Geralmente ocorre em pacientes que apresentam intensa imunossupressao, ou em paci entes que não apresentam evidências de imunossupressão mas compatibilidade do sistema HLA.

A única forma segura de abordagem da DECHT é a profilaxia através da irradiação gama dos hemocomponentes. As mudanças nas características dos hemocomponentes induzidas pela irradiação, o custo e a necessidade de garantir a efi ciência do processo, fazem com que seja necessário definir os pacientes que necessitam receber hemocomponentes irradiados, o período de estocagem após a irradiação e a dose de irradiação a ser empregada.

Neste estudo são revistos os aspectos clínicos, imunofisiopatológicos e tratamento da DECHT. F oram analisados vários casos clínicos de DE CHT publicados, procurando abranger as diferentes doenças de base relacionadas ao aparecimento da síndrome, para elaboração de um guia de irradiação de hemocomponentes.

\section{MANIFESTAÇÕES CLÍNICAS}

A DE CHT foi reconhecida em seres humanos em 1965, após a transfusão de sangue fresco em duas crianças com suspeita de síndrome de imunodeficiência congênita ${ }^{8}$. Foram posteriormente descritos novos casos em crianças imunodeficientes, doentes oncológicos, pacientes submetidos a transplantes de medula óssea, crianças que receberam transfusão intra-útero seguida de exsanguíneo transfusão ao nascimento e em pacientes considerados imunocompetentes (Tab.1).

A incidência real da DECHT é desconhecida mas foi estimada entre $0,1 \%$ e $1 \%$ dos pacientes com neopiasias hematológicas ${ }^{9}$. J uji et al., enviaram questionários a 340 hospitais no J apão e conseguiram identificar 96 pacientes que preenchiam critérios para DECHT em 63.257 cirurgias cardíacas. A incidência foi calculada em um para cada 659 cirurgias que usaram sangue e a mortalidade foi estimada em $90 \%{ }^{10}$.

Appleton et al., ${ }^{11}$ fizeram levantamento retrospectivo de $\mathrm{DECH}$ não relacionada a TMO, em servi ço de anatomia patológica. E m um período de 3 anos verifi caram 9 casos suspeitos de DE CHT em pacientes que estavam recebendo tratamento quimioterápico. Esses autores sugeriram que a síndrome possa ser mais freqüente que o encontrado e que provavel mente seja subdiagnosticada.

Com o intuito de determinar os principais fatores de risco envolvidos no aparecimento da DECHT, Takashashi et al., analisaram dados de 171 pacientes com diagnóstico de DECHT, no J apão. Os principais fatores de risco envolvidos foram transfusão de sangue fresco, consanguinidade, realização de cirurgias cardíacas, doenças neoplásicas e pertencer ao sexo masculino. Verificaram também que a síndrome é mais prevalente em idade superior a 50 anos $^{12}$.

A evol ução da DECHT é geralmente agressiva e fatal, sendo que a mortali dade está estimada entre 90 a $100 \%{ }^{13}$.

A DECHT manifesta-se inicialmente com febre de causa indefinida, em período que pode variar de 4 a 30 dias após a transfusão ${ }^{14}$. N a presente revisão de literatura a febre iniciou em média 11 dias após a transfusão. Em um intervalo de 24 a 48 horas após o início da febre, surge erupção cutânea eritematosa, máculo papular, em face e tronco, com rápida progressão para as extremidades, podendo ocorrer formação de bolhas e processo esfoliativo. Sintomas como anorexia, náuseas, vômitos e diarréia normalmente iniciam-se juntamente com as manifestações cutâneas. A diarréia freqüentemente é aquosa e profusa ( 5 a 8 litros por dia). Raramente apresenta-se sanguinolenta, sendo a presença de sangue decorrente de ulcerações em todo tubo digestivo.

As manifestações hepáticas podem ocorrer concomitantemente, ou em seguida ao acometimento cutâneo. São caracterizadas clinicamente por hepatomegalia dolorosa eicterícia, por el evação sérica de alanina aminotransferase (ALT), fosfatase alcalina (FA), desidrogenase láctica ( $D H L$ ) e bilirrubinas (BT). A intensidade das alterações laboratoriais parece ser diretamente proporcional à intensi dade do acometimento hepático.

A ação dos linfócitos T transfundidos sobre as células hematopoéticas precursoras pode levar a hipoplasia ou aplasia da medula óssea e consequentemente a pancitopenia. O tempo para o aparecimento da pancitopenia variou de 7 a 24 dias ápos a transfusão.

Os achados típicos encontrados na análise histopatológica da pele consistem em degeneração picnótica das células da epiderme, com a presença de um ou mais linfócitos satélites e degeneração vacuolar com infiltrado linfocitário difuso da camada basal e parte superior da derme ${ }^{15}$. O tubo digestivo apresenta úlceras de fundo necrótico com infil trado linfoci tário evi dente. No fígado são encontrados infiltrados linfocitários em áreas peri-portais com necrose dos hepatócitos. A medula óssea apresenta hipoplasia de moderada a severa ou aplasia. Poderão ser encontrados histiocitose, plasmocitose, eritrofagocitose e linfofagoci tose $^{16,17}$. Os tecidos linfóides, como baço el infono- 


\begin{tabular}{|c|c|c|c|c|c|c|c|c|c|c|c|c|c|c|}
\hline SIDC & $8 \mathrm{M}$ & $\mathrm{F}$ & 4 & Suspeita & Suspeita & $\mathrm{C}+\mathrm{P}$ & Sim & NR & NR & 12 & $\mathrm{CE}$ & NR & $\mathrm{CL}$ & 8 \\
\hline $\begin{array}{l}\text { T. intra-útero } \\
\text { Exsanguineo } \\
\text { Transfusão }\end{array}$ & $\mathrm{RN}$ & M & 12 & - & Autópsia & $\mathrm{C}+\mathrm{P}$ & Sim & $S$ & NR & NR & - & 17 & $\mathrm{CH}$ & 25 \\
\hline L. Hodgkin & 58 & $\mathrm{~F}$ & 13 & 29 & $\begin{array}{l}\text { Biópsia de } \\
\text { pele }\end{array}$ & $\mathrm{C}+\mathrm{P}$ & Sim & NR & B & 24 & $\mathrm{CE}+\mathrm{ATG}$ & 47 & $\mathrm{CH}$ & 67 \\
\hline L. Hodgkin & 18 & $\mathrm{~F}$ & 5 & 10 & $\begin{array}{l}\text { Biópsia de } \\
\text { pele }\end{array}$ & $\mathrm{C}+\mathrm{P}+\mathrm{B}$ & Sim & $A$ & B & 9 & - & $\begin{array}{c}\text { Não } \\
\text { obituou }\end{array}$ & $\mathrm{CH}$ & 33 \\
\hline L. Hodgkin & 31 & $\mathrm{~F}$ & 7 & 12 & $\begin{array}{l}\text { Biópsia de } \\
\text { pele }\end{array}$ & $\mathrm{C}+\mathrm{P}$ & NR & A & $E+B$ & 13 & $\mathrm{CE}+\mathrm{TMO}$ & NR & $\mathrm{CH}+\mathrm{CP}$ & 28 \\
\hline L. Hodgkin & 14 & M & 4 & $6-7$ & $\begin{array}{l}\text { Biópsia de } \\
\text { pele }\end{array}$ & $\mathrm{C}+\mathrm{P}$ & Sim & A & $E+B$ & NR & CE & 26 & $\mathrm{CP}$ & 24 \\
\hline LLA & 8 & $\mathrm{~F}$ & 28 & 30 & $\begin{array}{l}\text { Biópsia de } \\
\text { pele }\end{array}$ & $\mathrm{C}+\mathrm{PB}$ & Sim & A & $E+B$ & NA & CE & $\begin{array}{l}\text { Não } \\
\text { obituou }\end{array}$ & $\begin{array}{l}\mathrm{CH} \\
\mathrm{CL}\end{array}$ & 32 \\
\hline LMA & 61 & M & 7 & NR & $\begin{array}{l}\text { Biópsia de } \\
\text { pele }\end{array}$ & $\mathrm{C}+\mathrm{P}$ & Sim & A & $E+B$ & $\mathrm{NR}$ & CE & 19 & $\begin{array}{c}\text { CP HLA } \\
\text { compatível }\end{array}$ & 23 \\
\hline L. não-Hodgkin & 67 & $\mathrm{~F}$ & 15 & 17 & $\begin{array}{l}\text { Biópsia de } \\
\text { pele }\end{array}$ & $\mathrm{C}+\mathrm{P}$ & Sim & $A+S$ & B & 19 & CE & 33 & $\mathrm{CH}+\mathrm{CP}$ & 27 \\
\hline $\begin{array}{l}\text { L. não-Hodgkin } \\
\text { (2CDA) }\end{array}$ & 66 & $\mathrm{~F}$ & 7 & 14 & PCR & $\mathrm{C}+\mathrm{P}$ & Sim & A & E & 7 & CE & 16 & $\mathrm{CP}$ & 21 \\
\hline $\begin{array}{l}\text { LLC-B } \\
\text { (fludarabina) }\end{array}$ & 61 & $\mathrm{~F}$ & 21 & 30 & PCR & $\mathrm{C}+\mathrm{P}$ & Sim & NR & B & NR & $\mathrm{CE}+\mathrm{ATG}$ & 35 & $\mathrm{CH}+\mathrm{CP}$ & 20 \\
\hline Neuroblastoma & 2 & M & 7 & $7-10$ & $\begin{array}{l}\text { Biópsia de } \\
\text { pele }\end{array}$ & $\mathrm{C}+\mathrm{P}$ & NR & A & $E+B$ & $7-10$ & $\mathrm{CE}+\mathrm{ATG}$ & $N R$ & $\mathrm{CH}$ & 37 \\
\hline Cirurgia cardíaca & 69 & M & 18 & - & HLA & $\mathrm{C}+\mathrm{P}$ & SIM & NR & $E+B$ & 22 & CE & 22 & ST & 16 \\
\hline Cirurgia cardíaca & 53 & M & 14 & 17 & $\begin{array}{l}\text { Biópsia de } \\
\text { pele+HLA }\end{array}$ & $\mathrm{C}+\mathrm{P}$ & Sim & NR & $E+B$ & 17 & $\mathrm{CE}+\mathrm{ATG}$ & 33 & ST & 16 \\
\hline Cirurgia cardíaca & 63 & M & 12 & 22 & $\begin{array}{l}\text { Biópsia de } \\
\text { pele }\end{array}$ & $\mathrm{C}+\mathrm{P}+\mathrm{B}$ & Sim & A & $E+B$ & 22 & CE & 26 & ST & 38 \\
\hline Colecistectomia & 52 & $\mathrm{~F}$ & 10 & - & Suspeita & $\mathrm{C}+\mathrm{P}$ & $\operatorname{Sim}$ & A & $\mathrm{E}$ & 17 & $\mathrm{CE}$ & 28 & $\mathrm{CH}$ & 35 \\
\hline $\begin{array}{l}\text { Cirurgia } \\
\text { ortopédica }\end{array}$ & 77 & $\mathrm{~F}$ & 13 & 30 & $\begin{array}{l}\text { Biópsia de } \\
\text { pele }\end{array}$ & $\mathrm{C}+\mathrm{P}$ & Sim & A & NR & 23 & - & 35 & $\mathrm{CH}$ & 39 \\
\hline $\begin{array}{l}\text { Gestação + } \\
\text { Cesariana }\end{array}$ & 32 & $\mathrm{~F}$ & 9 & 13 & $\begin{array}{l}\text { Biópsia de } \\
\text { pele }\end{array}$ & $\mathrm{C}+\mathrm{P}$ & Sim & NR & $E+B$ & 13 & $\mathrm{CE}+\mathrm{ATG}$ & $\begin{array}{c}\text { Não } \\
+ \text { +Anti-CD3 }\end{array}$ & $\begin{array}{c}\mathrm{CH} \\
\text { obituou }\end{array}$ & 31 \\
\hline $\begin{array}{l}\text { LMC } \\
\text { TMO Alogênico }\end{array}$ & 34 & $\mathrm{~F}$ & NR & NR & $\begin{array}{l}\text { Cariótipo+ } \\
\text { PCR }\end{array}$ & $\mathrm{C}+\mathrm{P}$ & $N R$ & A & $N R$ & - & TMO & 96 & $\mathrm{CH}+\mathrm{CP}$ & 22 \\
\hline $\begin{array}{l}\text { LLC - B } \\
\text { (Fludarabina) }\end{array}$ & 61 & M & 10 & NR & $\begin{array}{l}\text { Biópsia de } \\
\text { pele }\end{array}$ & $\mathrm{C}+\mathrm{P}+\mathrm{B}$ & Sim & $N R$ & $\mathrm{E}+\mathrm{B}$ & 21 & $\mathrm{MTX}+\mathrm{CE}$ & 26 & $\mathrm{CH}$ & 64 \\
\hline $\begin{array}{l}\text { LLC - B } \\
\text { (Fludarabina) }\end{array}$ & 47 & M & NR & NR & $\begin{array}{l}\text { Biópsia de } \\
\text { pele }\end{array}$ & $\mathrm{C}+\mathrm{P}$ & Sim & A & $E+B$ & NR & CE & NR & $\mathrm{CH}$ & 64 \\
\hline Doença de Paget & 60 & $\mathrm{~F}$ & 12 & 15 & $\begin{array}{l}\text { Biópsia de } \\
\text { pele }\end{array}$ & $\mathrm{C}+\mathrm{P}$ & Sim & - & $E+B$ & 16 & CE & 17 & $\mathrm{CH}+\mathrm{ST}$ & 65 \\
\hline \multicolumn{15}{|c|}{$\begin{array}{l}\Delta t \text { (dias) Sintomas - intervalo de tempo entre a transfusão e o início dos sintomas, } \Delta \mathbf{t} \text { (dias) Diag. - intervalo de tempo entre a transfusão e o diagnóstico, Diag. } \\
\text { método diagnóstico, Pele C - acometimento cutâneo do tronco, Pele P - acometimento cutâneo periférico, Pele B - formação de bolhas, Diarréia } \mathbf{A} \text { - Diarréia aquosa } \\
\text { Diarréia S- diarréia sanguinolenta, Fígado E - alteração de enzimas hepática, Fígado B - alteração de bilirrubinas, } \Delta \mathbf{t} \text { (dias) Pancitopenia - intervalo de tempo entre } \\
\text { a transfusão e o aparecimento de pancitopenia, } \Delta \mathbf{t} \text { (dias) óbito - intervalo de tempo entre a transfusão e a ocorrência do óbito, SIDC - síndrome de imunodeficiência } \\
\text { congênita, LLA - leucemia linfóide aguda, LMA - leucemia mielóide aguda, LLC-B - leucemia linfocítica crônica B, GMSI - gamopatia monoclonal de significado } \\
\text { indeterminado, LMC - leucemia mielóide crônica, TMO - transplante de medula óssea, CE - corticosteróides, ATG - imunoglobulina antitimocítica, MTX - methotrexate } \\
\text { 2-CDA - 2-clorodeoxiadenosina, CsA - ciclosporina A, PCR - reação de polimerase em cadeia, ST - sangue total, CH - concentrado de hemácias, CP - concentradd } \\
\text { de plaquetas, CL - concentrado de leucócitos, NR - não relatado. }\end{array}$} \\
\hline
\end{tabular}


Quadro 1 - Situações relacionadas à dificuldade diagnóstica da DECHT.

1 - Desconhecimento da síndrome.

2 - Manifestação febril em paciente imunossuprimido sugerindo infecção.

3 - Rash cutâneo sugestivo de farmacodermia ou infecção viral.

4 - Longo intervalo de tempo entre a transfusão e o início dos sintomas dificultando estabelecimento de nexo causal.

5 - Presença de doenças associadas.

6 - Raridade do evento.

7 - Curso rápido e fatal.

Quadro 2 - Indicações de Irradiação de Hemocomponentes

1 - Indicações Absolutas

a - Transfusões entre familiares.

b - Transfusões HLA compatíveis.

c - Transplantes de medula óssea autólogos e alogênico.

d - Doença de Hodgkin.

e - Pacientes tratados com análogos da purina.

f - Transfusões intra-útero.

\section{2 - Indicações Recomendadas}

a - Pacientes com neoplasia submetidos a protocolos de quimioterapia agressivos.

b - Recém-nascido pré-termo.

3 - Indicações não Definidas

a - Cirurgias cardíacas.

b - Transplantes de órgão sólidos.

c - Síndrome da imunodeficiência adquirida.

d - Recém-nascido a termo.

e - Exsanguíneo transfusões.

dos, apresentam-se atrofiados com aumento de células histioc itárias ${ }^{18}$.

\section{DIAGNÓSTICO}

O diagnóstico geralmente é feito pelo quadro clínico associado ao exame histopatol ógi co da pele. A presença de cél ulas expressando antígenos HLA diferentes do HLA do receptor e, se possível, a sua correlação com os antígenos HLA do doador, ajudam a confirmar o diagnóstico.

A pancitopenia dificulta a detecção de antígenos HLA do hospedeiro a partir de amostras de sangue. Determinando o HLA dos familiares, pode-se recorrer a confecção de heredogramas e determinar o provável HLA do hospedeiro. Pode-se também determinar o HLA do hospedeiro a partir de cultura de fibroblastos obtidos em fragmentos de biópsia de pele ${ }^{19}$. O uso da técnica de reação de polimerrase em cadeia (PCR) para detecção de DNA exógeno tem sido utilizada com sucesso na confirmação da DE CHT 20,21,22.

Nos casos estudados, o tempo necessário para estabelecer o diagnóstico variou de 2 a 16 dias após o iníci o dos sintomas. Freqüentemente, não havia hipótese diagnostica de DECHT antes do resultado da biópsia de pele $\mathrm{e}^{23,24}$, ou o diagnóstico foi realizado somente após a autópsia17,18,25.

A manifestação inicial de febre na DECHT leva à suspeita de processo infeccioso. Como geralmente trata-se de paciente imunossuprimido, introduz-se terapia antimicrobiana o que confunde o rash cutâneo com farmacodermia ou exantema de eti ol ogia viral e consequentemente há retardo no diagnóstico. As principais causas de retardo no diagnóstico da DECHT estão sumarizadas no Quadro 1.

A quebra de barreiras devido à formação de úlceras em pel e e trato digestivo, somada à hipoplasia ou aplasia de medula óssea, propiciam a infecção por patógenos e consequente septicemia. Os óbitos são, geralmente, decorrentes de complicações infecciosas. Em pacientes com hemoculturas negativas durante o curso da doença foi verificada na autópsia, a presença de infecção fúngica ${ }^{16,17,26,27,28}$.

\section{TRATAME NTO}

O tratamento para a DECHT não está definido. A terapêutica mais empregada foi o uso de corticoesteroides em altas doses isoladamente, ou em associação com a gamaglobulína antitimocítica. Biundell et al., utilizaram prednisol ona e ciclosporina A (CSP) com sucesso no tratamento de uma paciente com gamopatia monoclonal de significado indeterminado que desenvolveu $\mathrm{DECHT}^{29}$. Neste caso as manifestações clínicas foram atípicas, de longa evolução e o acometimento foi exclusivamente cutâneo de leve intensi dade. Há outro relato de DECHT onde ciclosporina (CSP) e corticosteróide foram utilizados para o tratamento e a resposta terapêutica não foi adequada ${ }^{30}$. Spitzer et al., relataram a realização de TMO alogêni co, com compatibilidade HLA parcial, em um paciente com doença de Hodgkin que desenvolveu DECHT. Porém o paciente evoluiu para óbito no segundo dia pós TMO devido à septicemia ${ }^{28}$. Yasukawa et al., relataram o sucesso terapêuti co com o uso de anti CD3, CSP e metil predinisol ona em altas doses em uma paciente puérpera que desenvolveu DECHT após transfusão de concentrado de hemácias HLA compatível. O uso do anti-CD3 talvez inicie uma nova perspectiva de tratamento para a DECHT.

Muito interessantes foram os relatos de dois 
pacientes, um em tratamento quimi oterápico para leucemia linfóide aguda e outro para doença de Hodgkin. Esses pacientes desenvolveram DECHT com manifestações completas e intensas, e obtiveram regressão completa e espontânea dos sintomas $^{32,33}$. N os dois casos a transfusão que originou a DECHT coincidiu com a administração de quimioterápi cos para tratamento da doença de base sugerindo que a ação dos quimioterápicos limitou a proliferação dos linfócitos transfundidos.

Deve-se considerar com cautela a proposta de tratamento da DECHT utilizando-se agentes quimioterápicos, pois se fossem empregados quando estabel ecido o diagnóstico, não haveria tempo hábil para o efeito terapêutico. No entanto, a opção por transfundir no mesmo dia da aplicação de qui mi oterápi cos poderá vir a aumentar a segurança transfusional quanto à prevenção da DECHT.

Não é possível afirmar se a má evolução dos pacientes é decorrente retardo no diagnóstico ou se relacionado ao baixo índice de resposta terapêutica. Os pacientes que receberam tratamento convencional e evoluíram para óbito, estes ocorreram entre 11 e 47 dias após a transfusão, em média 24 dias. Se considerarmos que o tempo necessário para o estabel ecimento do diagnóstico variou de 7 a 30 dias após a transfusão, em média 20 dias, pode-se concluir que dispunha-se de tempo exíguo para obtenção de algum efeito terapêutico.

\section{MECANISMO DA DECHT}

Para a DECHT se desenvolva, o hemocomponente transfundido deverá conter linfócitos viáveis e em número adequado ${ }^{18}$. Concomitantemente o hospedeiro deverá encontrar-se em estado de imunossupressão que o incapacite de reconhecer e estabel ecer resposta contra antígenos estranhos ${ }^{34}$.

Podem ocorrer três situações clínicas diferentes onde o hospedei ro encontra-se suscetível ao desenvolvimento da DECHT:

Estado de imunossupressão severa a ponto de não haver resposta imunológica contra os linfóci tos transfundidos mesmo que haja diferenças no complexo de histocompatibilidade principal. Esta situação pode ser observada na doença de Hodgkin, nos TMOs e em algumas síndromes de imunodeficiência congênita ${ }^{5,8,28}$.

Compatibilidade HLA entre o hospedeiro e os linfócitos transfundidos. Geralmente os linfócitos transfundidos são homozigotos para as proteínas HLA (aa) as quais o hospedeiro é heterozigoto (ab). A resposta imunológica do hospedeiro ficará prejudicada à medida que não reconhece as proteínas HLA dos linfócitos transfundidos (aa) como estranhas ${ }^{16,19,35}$.
Transfusão intra-útero seguida de exsanguíneo transfusão ao nascimento, de preferência do mesmo doador. Os linfócitos transfundidos intra-útero, devido a imaturidade do sistema imunol ógico fetal, podem permanecer víaveis no recém nascido por longos períodos após o nascimento sem qualquer manifestação evidente ${ }^{25}$. A DECHT ocorrerá somente após a exsanguíneo transfusão, onde os novos linfócitos encontrarão condições para sua ativação e proliferação, devido a maior maturidade do si stema imunológico. Ao mesmo tempo, esses linfócitos não são reconhecidos como estranhos pois a transfusão intra-útero induziu à tol erância imunológica das proteínas HLA do doador ${ }^{36}$.

I ndependente da situação clínica que propiciou o desenvol vimento da DECHT, a presença de imunodeficiência, em diferentes graus, deve ser considerada como fator fundamental. A presença de compatibilidade total ou parcial das proteínas HLA pode favorecer o desenvolvimento da DECHT, porém não pode ser consi derada o único fator predisponente. Os relatos de DECHT em indivíduos considerados imunocompetentes, favorecida pela compati bilidade das proteínas HLA, não consideraram tratamentos quimioterápicos e radioterápicos, a presença de doença neoplásica e as intervenções cirúgicas como possíveis agentes imunossupressores ${ }^{19,30,35,37-39}$. As cirurgias cardíacas, por exemplo, estão relacionadas ao aparecimento de linfopenias al ém de di minuir a atividade dos linfócitos T na primeira semana do período pós operatóri $\mathrm{o}^{40}$. Deve também ser considerado o fato de um organismo imunocompetente ter condições de rejeitar células HLA compatíveis, em virtude das diferenças nos antígenos de histocompatibilidade menores ${ }^{34}$ e o grande número transfusões HLA compatíveis anualmente realizadas e a raridade do aparecimento da $\mathrm{DECHT}^{41}$.

Lee et al., ${ }^{42}$ usando a técnica de PCR quantitativo analisaram a cinética dos linfócitos após a transfusão de concentrado de hemácias de doadores não relacionados em indivíduos imunocompetentes. Os autores observaram redução significativa dos linfóci to transfundidos nos dois primeiros dias após transfusão seguido de aumento (aproximadamente 1-log) entre o terceiro e o quinto dia e posteriormente redução definitiva. Em model os animais, no mesmo estudo, quando havia sensibilização pregressa, não se evidenciavam aumentos no número de linfócitos indicando resposta imunológica mais precoce ${ }^{42}$. Os achados sugerem que os linfócitos transfundi dos normalmente se proliferam antes que a resposta imunol ógica do hospedeiro determine o limite desta proliferação. Nos hospedeiros imunoincompetentes, ou em 
situações onde a compatibilidade HLA entre os linfócitos transfundidos e hospedeiro venha provocar um retardo da resposta imunológica, a excessiva proliferação dos linfócitos transfundidos poderia favorecer o aparecimento da DECHT.

A pele, o tubo digestivo e o fígado são acometidos precocemente e de forma intensa, enquanto órgãos como rins, coraçao e glândul as endócrinas normalmente não são agredidos. A intensidade da agressão de um tecido por mecanismo de $\mathrm{DECH}$ parece estar diretamente relacionada ao número de CAA presentes nesse tecido ${ }^{43}$. Como a pele, o tubo digestivo e o fígado são freqüentemente estimulados por antígenos externos, é natural que contenham maior quanti dade de teci do linfói de e consequentemente maior número de CAA.

A imunofisiopatologia da DECHT é semel hante à $\mathrm{DECH}$ pós TMO alogênico. Nos TMOs alogênicos, o regi me de condicionamento provoca dano tissular favorecendo a secreção de citoquinas como interleucina-1 (IL-1) e fator de necrose tumoral alfa (TNF alfa), capazes de aumentar a expressão das moléculas do CHP favorecendo a adesão dos linfócitos $\mathrm{T}$ do doador ${ }^{44}$. Os lipopolissacárides provenientes da lesão de células da mucosa intestinal (por ação de quimioterapia, radioterapia ou da própria $D E C H$ ), estimulam os queratinócitos, fibroblastos e macrófagos a produzirem TNF alfa o que aumenta o efei to inflamatório local e induz a apoptose celular². O mesmo pode ocorrer na DECHT, em menor intensidade, à medida que os pacientes geralmente encontravam-se em tratamento quimioterápico, radioterápico, ou sofreram cirurgias ${ }^{45}$. Os linfócitos T histoincompatíveis, viáveis e em número suficiente, quando transfundidos em um indivíduo incapaz de desenvolver resposta imunológica satisfatória, reconhecem os pepitídeos HLA das CAA do hospedeiro e sofrem ativação e diferenciação (fase aferente). A ligação dos pepitideos HLA das CAA com o receptor dos linfócitos transfundidos, a ação da IL-1 e o sinal coestimulatório da interação das moléculas B7-CD8, faz com que haja estimulação desses linfócitos ${ }^{1}$. A interleucina-2 (IL-2) produzida pelo próprio linfócito ativado (efeito autócrino) ou pel o hospedeiro (efeito parócrino), juntamente com o interferon gama (IF N gama) do hospedeiro, irá promover a proliferação e diferenciação desses linfócitos. Se a molécula do complexo de histocompatibilidade da CAA envolvida no reconhecimento for de casse II (HLA DR, $D P, D Q)$ a proliferação e diferenciação será de células CD4 e se classe I $(A, B, C)$ a proliferação e diferenciação será de células $C D 8^{44}$. Os linfócitos $\mathrm{T}$ ativados irão atuar diretamente, ou indireta-

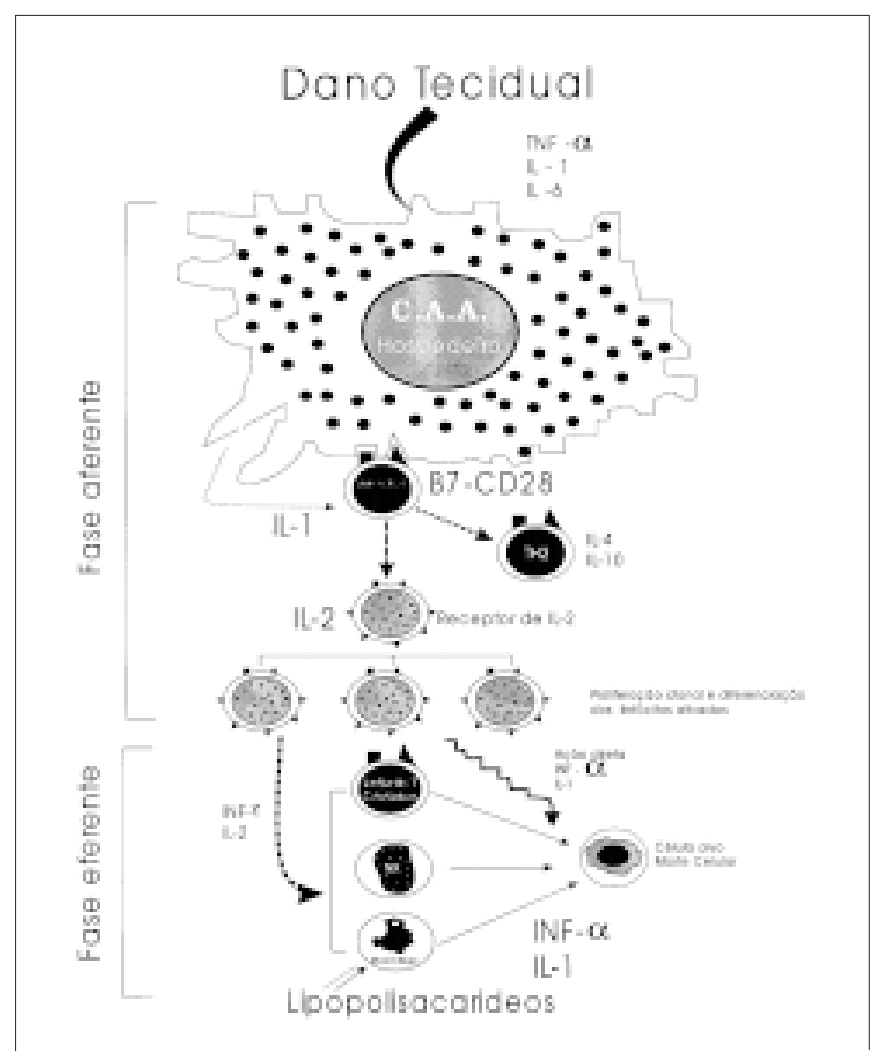

Fig. 1 - Fisiopatologia da DECH. A ação de quimioterapia, radioterapia, ou outras situações que provoquem dano teci dual, promovem a li beração deTNF - $\alpha$, I L-1 el L6. Essas citoquinas irão aumentar a expressão das molé culas do CHP das células apresentadoras de antígenos (CAA). Os infócitos T do doador ligam-seao CHP das CAA e são ativados pela ação da IL-1 e efei to coestimulatório das moléculas B 7-CD28. Esses I infócitos quando diferenciados para células Th1, sofrem auto-ativação pela ação da IL-2 e é induzido a proliferação. As células Th1 irão produzir INF- $\gamma$ e IL-2 que estimulam os Iinfócitos T citotóxicos, células NK e macrófagos do hospedeiro a produzirem infl amação teci dual e morte das células alvo. A diferenciação para células Th2 promove a liberação de IL-4 e IL-10, com efeito inibitório em todo processo. A inflamação tecidual e morte das células alvo poderá também ocorrer por ação direta do TNF- $\alpha$ e IL-1 das células Th1, ou pelos macrófagos do hospedeiro quando estimulados pelos lipopolissacarideos provenientes da lesão das células da mucosa intestinal.

mente através do recrutamento de células "natural killer" (NK) elinfócitos do próprio hospedeiro, originando maior dano tecidual e favorecendo a perpetuação do processo (fase aferente) (Fig-I). A agressividade das manifestações dependerá da proporção entre linfócitos tipo 1 (Thl) e tipo 2 (Th2) independente de serem CD4 ou CD8. As células Thl produzem IL-2 e IFN gama, citoquinas relacionadas à perpetuação e intensificação da DECH. As células Th2 produzem interleucina-4 (IL-4) e interleucina-10 (IL-10) com efeito inibitório sobre as células $\operatorname{Th}^{16}{ }^{46}$. Não são 
conhecidos quais os fatores que determinam a diferenciação das células para Thl ou Th2.

\section{GUIA DE IRRADIAÇÃO DE HEMOCOMPONENTES}

Considerando-sea baixíssi ma resposta ao tratamento e a el evada mortalidade, a irradiação gama dos hemocomponentes é a única forma segura de prevenir o aparecimento DECHT.

O uso de irradiação ultra-violeta B em concentrados de plaquetas, em doses que inibam a reatividade dos linfócitos em cultura mista, não prejudica a função plaquetária in vivo, mas até o momento não há dados suficientes para considerá-la segura na prevenção da $\mathrm{DECHT}^{47}$.

Dzik \& J ones ${ }^{42}$, compararam o efeito da irradiação gama com o efeito da redução do número de células em cultura mista de linfócitos (CML). Verificaram declínio de $95 \%$ na resposta da células estimuladas em CML com 600cGy de irradiação, ou com a redução do número de cél ulas efetoras de $2,5 \times 10^{6}$ para $7 \times 10^{5}$ (redução de 0,6 $\log _{10}$ ). Sugeriram que apesar da redução do número de leucócitos não ser considerada segura, o risco relativo de desenvolver DECHT na transfusão de hemocomponentes filtrados talvez seja menor que nas transfusões sem filtro.

Os filtros usados em transfusão de hemácias e plaquetas removem mais de 97\% dos leucócitos garantindo a infusão de menos de $10^{8}$ leucócitos por unidade de concentrado de hemácias ou pool de 10 unidades de concentrado de plaquetas. U sandose model os animais estimou-se serem necessários $10^{7}$ linfócitos por quilo de peso do receptor para o desenvovimento de $\mathrm{DECHT}^{18}$. Dependendo das condi ções imunol ógi cas do hospedei ro este número poderia ser menor ${ }^{27}$.

Desta forma, o uso de filtros de leucócitos também não deve ser considerado como método seguro na prevenção da DECHT, desde que não está definido o número de linfócitos viáveis necessários para o desenvolvimento de DE CHT. Soma-se a isto o relato de caso de DECHT com o uso de hemocomponentes filtrados ${ }^{27}$.

Os filtros de leucócitos agem fundamental mente na prevenção da al oi munização. Este efei to não é garantido pela irradiação uma vez que não há alteração na conformação antigênica ou perda da função celular pela irradiação. Desta forma, a irradiação dos hemocomponentes não exclue a necessidade de uso de filtros de leucócitos quando se deseja prevenir a aloimunização.

Até o momento não existem dados na literatura que comprovem a necessidade de irradiação de hemocomponentes acelulares como plasma fresco congelado, plasma preservado, criopreci pitado ou qualquer outro componente derivado de plasma. Após o congelamento e descongel amento do plasma fresco, os linfócitos perdem a capacidade de prol iferação ${ }^{49}$. As orientações contidas nesse guia sobre dose de irradiação, mudanças nas características dos hemocomponentes irradiados e as indicações de irradiação, referem-se apenas ao sangue total, concentrado de hemácias, concentrado de plaquetas e concentrado de leucócitos. A transfusão de concentrado de leucócitos apesar de ser pouco freqüente, é a de maior risco devido ao uso quase imediato após col eta, ao el evado número del infócitos e por destinar-se a pacientes imunoincompetentes.

\section{I - Dose de irradiação}

A dose inicialmente preconizada para irradiação de hemocomponentes era de 1500 cGy, a qual era baseada na dose para obtenção de células estimuladoras em cultura mista de linfócitos. O rel ato do apareci mento de DE CHT em um paciente submetido a TMO alogênico após a transfusão de hemocomponentes irradiados com 2000 cGy, provocando rejeição da medula transplantada ${ }^{22}$, fez com que muitos centros realizassem estudos para determinação a dose segura de irradiação. Essa dose não deveria comprometer a viabilidade das células, ou acarretar mudanças nas características dos hemocomponentes.

Rosen et al. ${ }^{50}$, utilizando cultura mista de linfócitos, compararam o crescimento de amostras não irradiadas com as amostras correspondentes que receberam doses escalonadas de irradiação gama variando de 500 cGy a 5000 cGy. Demonstraram que todas as mitoses são suspensas com doses entre 2500 e 3000 cGy. Este resultado foi posteriormente confirmado, utilizando-se técnica mais sensível na quantificação dos linfócitos T da cultura mista, após a estimulação51.

\section{II - Alterações nos Hemocomponentes provocadas por irradiação e estocagem}

O período de estocagem dos hemocomponentes após a irradiação não está definido. É recomendável que os hemocomponentes sejam irradiados imediatamente antes da sua utilização.

Hillyer et al..$^{52}$, compararam as características de frações irradiadas com 3500 cGy com frações não irradiadas de um mesmo concentrado de hemáci as e evi denciaram que al ter ações como: el evação de $\mathrm{K}^{+}$, fosfogl icerato qui nase, $\mathrm{DHL}$, redução de $\mathrm{Na}^{+}$, ATP e $\mathrm{pH}$, foram mais evidentes nas frações irradiadas. E ssas alterações não foram consideradas significativas até o $28^{\circ}$ dia de estocagem. Não 
foi estudado a recuperação das hemácias in vivo para verificar se o dano celular comprometeria a sobrevida das hemácias após a transfusão. Davey et al. ${ }^{53}$, usaram hemácias de voluntários para transfusão autóloga. Essas hemácias foram marcadas e estocadas por 42 dias. Compararam a recuperação in vivo da fração irradiada com 3000 cGy com a fração não irradiada do mesmo concentrado de hemácias. A recuperação das hemácias após 24 horas da transfusão foi de $68,5 \pm 8,1 \%$ e $78,4 \pm 7,1 \%$ para as hemácias irradiadas e não irradiadas respectivamente. Concluíram que a irradiação provoca danos à membrana dos eritrócitos e as unidades de concentrado de hemácias não devem ser estocadas até o limite da data de validade após terem sido irradiadas.

$\mathrm{O}$ aumento significativo dos níveis de $\mathrm{K}^{+}$nos concentrados de hemácias irradiados sugere que a irradiação leve a alter ações no mecanismo regulador das concentrações de $\mathrm{Na}^{+}$e $\mathrm{K}^{+}$da membrana das hemácias. A el evação nos níveis de $K^{+}$é progressiva após 24 horas de estocagem dos concentrados de hemácias irradiados. Essas alterações tendem a aumentar com o tempo, tornando-se significativas por volta do $14^{\circ}$ dia de estocagem ${ }^{54}$.

As concentrações de $\mathrm{K}^{+}$nos concentrados de hemácias têm pouca importância para transfusão em adultos com função renal preservada. Em pacientes pediátricos é recomendada a lavagem manual dos concentrados de hemáceas, caso não sejam infundidos no período de 24 horas após a irradiação ${ }^{55}$.

Não foram observadas al terações nas características e nas funções celulares dos concentrados de leucócitos e concentrados de plaquetas quando irradiados a 3000 cGy e posteriormente estocados ${ }^{56}$. I sto talvez se deva ao curto período de estocagem desses hemocomponentes.

\section{III - Indicações de utilização de homcompo- nentes irradiados}

1 - I rradi ação de hemocomponentes para indi víduos imunocompetentes:

\section{a) Doações de de familiares}

Kanter ${ }^{57}$ estudou através de cál cul os matemáticos a probabilidade de transfusão de hemocomponentes com haplótipos HLA idênticos em doações específicas provenientes de familiares. Não evidenciou diferenças na probabilidade de transfusão de haplótipos idênticos entre familiares diretamente relacionados como irmãos, pais, avós, netos, tios e primo ${ }^{57}$. Entretanto, populações com elevada prevalência de alguns haplótipos HLA como J apão, Canadá, Alemanha, bem como comunidades restritas, com casamentos consangüíneos, apresentam risco de transfusão de cél ulas hapl oidênticas em transfusões entre não aparentados não semel hante às transfusões entre parentes de outras populações ${ }^{58}$.

No Brasil, devido à miscigenação racial, presume-se que a ocorrência de haplótipos de alta prevalência seja rara. I sto torna a possibilidade de desenvolvimento de DECHT, favorecida pela semelhança HLA, extremamente baixa entre transfusões não apresentadas. Deve-se considerar ainda a dimi nuta possi bilidade de união de indi víduos com haplótipos semelhantes, desfavorecendo a ocorrência de filhos com HLA idêntico a um dos pais e consequentemente reduzindo a possibilidade de infusão de células hapl oi dênticas em transfusões entre familiares.

A irradiação de hemocomponentes de doações específicas para transfusão em familiares diretamente relacionados é bastante discutível. Doações específicas entre familiares são relativamente comuns em todo o mundo enquanto os relatos de DECHT são extremamente $\operatorname{raros}^{41}$.

Por medida de segurança, é aconsel hável a irradiação dos hemocomponentes de doações específicas quando oriundos de familiares em primei ro grau como país, filhos, irmãos, avós, netos, primos e tios.

\section{b) Doações HLA compatíveis}

A semel hança das proteínas HLA entre as células do hemocomponente e o receptor pode prejudicar o reconhecimento dos linfócitos infundidos como células estranhas e favorecer a sua proliferação e atividade ${ }^{59}$.

É indicado irradiar as unidades de concentrado de plaquetas HLA compatíveis destinadas aos pacientes com refratariedade à transfusões de plaquetas por sensibilização HLA.

\section{c) Cirurgias cardíacas}

Os vários relatos de DECHT em pacientes submetidos a cirurgia cardíaca não justificam a irradiação de hemocomponentes a serem utilizados nesse procedimento. Como é necessário haver histocompatibilidade entre linfócitos transfundidos e o paciente, as cirurgias cardíacas não constituem risco isolado para o desenvolvimento de DE CHT. A irradiação deve ser restrita às doações específicas de familiares, ou doações em comunidades com prevalência significativa de determinados haplótipos.

2 - I rradiação de hemocomponentes em indi víduos imunossuprimidos.

\section{a) Pacientes submetidos a transplantes de medula óssea alogênico}

O regime de condicionamento para a realização do transplante, o uso de medicamentos imunos- 
supressores e as modificações no sistema imunológico, fazem com que estes pacientes não consigam estabelecer resposta imunológica adequada. Esses pacientes apresentam altíssi mo risco de desenvolvimento de DECHT principal mente nos primeiros 6 meses após o TMO ${ }^{60}$. Como a presença de DECH crônica leva a estado de imunossupressão, o período de uso de hemocomponentes irradiados deve ser prorrogado até o total desaparecimento das manifestações, ou indefinidamente. Alguns centros optam por usar hemocomponentes irradiados em qualquer período após $\mathrm{TMO}^{9}$.

É indicado irradiar os hemocomponentes a serem usados nos transplantes de medula óssea al ogênico, do período de condicionamento até o término do uso da ciclosporina, ou indefinidamente.

\section{b) Pacientes submetidos a transplante de me- dula óssea autólogo}

Nos transplantes autól ogos o regime de condicionamento leva a imunossupressão intensa e a recuperação do sistema imunológico pode levar sei s meses após a infusão da medula óssea ${ }^{60}$. Atenção especial deve ser dada ao período da coleta de medula óssea, ou stem cell periférico, para posterior transplante autólogo. N esta fase, éfundamental irradiar todos os hemocomponentes a serem transfundidos, à medida que pode haver coleta e criopreservação dos linfócitos transfundidos, com conseqüente desenvol vimento de DECHT no período de recuperação após transplante ${ }^{61}$.

É indicado irradiar os hemocomponentes a serem utilizados nos transplantes de medula óssea autólogo, do período de col eta e cri opreservação da medula óssea até no mínimo 6 meses após o transplante.

\section{c) Pacientes com doença de Hodgkin}

A doença de Hodgkin éa condição clínica com maior número de relatos de $\mathrm{DECHT}{ }^{18}$. Além da imunossupressão induzida pelo tratamento quimioterápico e radioterápico, também é reconhecido o estado de imunossupressão relacionada à própria doença ${ }^{62}$.

É indicado o uso de hemocomponentes irradiados para pacientes com doença de Hodgkin em qualquer estágio da doença.

\section{d) Pacientes que receberam tratamento com análogos da purina (Fludarabina, 2 CDA, Pentostatina)}

O tratamento com análogos da purina induz prolongada depressão dos linfócitos CD $4^{63}$. Nesses pacientes, a DECHT pode ocorrer independente da compatibilidade HLA entre os linfócitos transfundidos e o receptor ${ }^{20,21,64}$. A indicação de irradiação dos hemocompomentes para transfusão nesses pacientes também está baseada no el evado número de casos publicados considerando-se o i nício recente da utilização dessas drogas 24,28 .

É indicado o uso de hemocomponentes irradiados em qualquer período após o tratamento com análogos da purina (Fludarabina, 2 CDA, Pentostatina).

\section{e) Outras doenças neoplásicas.}

Considerando a prevalência das leucemias agudas e linfomas não-H odgkin e o número de transfusões normalmente requeridas durante o tratamento, a incidência de DE CHT deve ser considerada baixa. Até o momento, não é possível fundamentar a indicação de irradiação dos hemocomponentes para este grupo de pacientes. O mesmo ocorre para pacientes em tratamento quimi oterápico ou radioterápico de tumores sólidos ${ }^{60}$. Os protocolos atuais de quimioterapia para tratamento de leucemias agudas e linfoma não-Hodgkin tornaram-se mais agressivos e consequentemente mais imunossupressores. O mesmo ocorre com os protocol os de quimi oterapia neoadjuvantes para tratamento dos tumores sólidos.

Se for considerada a possibilidade de aumento da prevalência de DECHT neste grupo de pacientes, é recomendável que os serviços adotem o uso de hemocomponentes irradiados. Não se deve porém, retardar uma transfusão por dificuldades na irradiação em serviços que não dispõem de irradiador de células ou serviço de radioterapia.

\section{f) Transplantes de órgãos sólidos}

Não há relatos de $\mathrm{DE} C \mathrm{CHT}$ relaci onada à realização de transplantes de órgãos sólidos, mesmo com a presença de imunussupressão induzida por medicamentos. O desenvolvimento de $\mathrm{DECH}$ nesses pacientes está relacionado a proliferação de linfócitos oriundos dos tecidos linfói des do orgão transplantado e não às transfusões ${ }^{6,7}$.

Não é necessário irradiar hemocomponentes para transfusão em pacientes submetidos a transplante de órgão sólido, ${ }^{9,60}$.

\section{g) Pacientes com síndrome de imunodefi- ciência adquirida}

Não há relatos de DECHT relacionada à transfusão em pacientes com síndrome de imunodeficiência adquirida (AIDS). O mecanismo de resistência ao desenvolvimento de DE CHT não é conhecido. Appleton et al. ${ }^{11}$ propuseram que a ausência de dano tecidual e a baixa produção de citoquinas estejam relacionado ao não desenvolvimento da DECHT. Não descartaram a possibilidade de a DECHT ser subdiagnosticada devido à complexicidade da sintomatologia desses pacientes ${ }^{11}$.

Até o momento, os pacientes com AIDS não podem ser considerados de risco para o desenvol- 
vimento da DECHT. Não é necessário irradiar hemocomponentes para transfusão nesse grupo de pacientes.

3 - I rradiação de hemocomponentes em neonatologia.

\section{a) Recém-nascido a termo}

As transfusões em recém nascidos a termo devem seguir os mesmos cuidados de uma transfusão em adulto imunocompetente. Deve-se porém, considerar a existência de síndrome de imunodeficiência congênita. As principais síndromes de imunodeficiência congênita envolvidas no aparecimento da DECHT foram: imunodeficiência combinada intensa e a síndrome de Wiskott - Aldrich ${ }^{28}$. A síndrome de Di George's, a digenesia reticular e outros estados de imunodeficiência celular não classificados também devem ser considerados na indicação do uso de hemocomponentes irradiados ${ }^{60}$. Há um relato latino americano de DECHT em criança com anemia de Blackfan-Diamond ${ }^{66}$. Não há relato de DECHT em pacientes com anemia de Fanconi.

Não é necessário irradiar hemocomponentes para transfusão em recém nascido a termo, exceto quando proveniente de doações específicas de familiares, ou quando houver suspeita de síndrome de imunoficiência congênita.

\section{b) Recém-nascido pré-termo}

A imaturidade do sistema imunológi co do recém nascido pré-termo pode favorecer a tol erância aos linfócitos provenientes de transfusões. O uso de transfusões repetidas de um mesmo hemocomponente aliquotado pode vir a aumentar o risco de desenvolvimento de DECHT nesses pacientes ${ }^{60}$.

A pesar de o risco de desenvol vimento de DECHT ser baixo nesses pacientes, é recomendável a utilização de hemocomponentes irradiados. Não devese porém, retardar uma transfusão por dificuldades na irradiação em hospitais que não dispõem de irradiador de células ou serviço de radioterapia.

\section{c) Transfusões intra-útero}

Não há relatos de DE CHT em transfusões intraútero isoladas. Deve ser considerada, no entanto o desenvolvimento de tolerância aos finfócitos transfundidos ${ }^{25}$ e a alta possibilidade de exsanguíneo transfusões ou simples transfusão após o nascimento. Esses fatores podem propiciar o desenvolvimento da DECHT.

É indicado irradiar todos os hemocomponentes a serem transfundidos intra-útero.

\section{d) Exsanguíneo transfusões}

Deve-se considerar o grande número de exsanguineo transfusões real izadas anual mente e a ausência de relatos de DECHT quando não há trans- fusão intra-útero pregressa. Este grupo de pacientes não pode ser considerado de risco para o desenvolvimento de DECHT.

É indicado irradiar os hemocomponentes destinados a exsanguíneo transfusões quando oriundos de doações específicas de familiares, quando destinados a recém nascidos pré-termo, quando houver transfusão intra-útero pregressa, ou evidências de síndrome de imunodeficiência congênita.

\section{SUMMARY}

Transfusion-associated graft-versus-host disease-guideline on gamma irradiation of blood components

Transfusion-associated graft-versus-host disease (TA-GVHD) is a rare and usuailly fatal syndrome. Clinical manifestations are fever, maculopapular skin rash, nausea, vomiting, diarrhea, hepatitis and pancytopenia owing to bone marrow hypoplasia. It can occur in recipients with severe immunossuppression and in immunocompetent recipients after transfusion of ceillular components from HLA homozygous donor to recipients heterozygous for that HLA haplotype. The diagnosis is made by clinical manifestation and skin biopsy. Antithymocyte gl obul in and high dose systemic corticosteroids areboth themost used therapy. Theback of knowl edge about this syndrome, the rapid evolution and the absence of treatement response are related to patients bad evolution. Gamma irradiation of blood products has been the mainstay of TA-GVHD prevention. Dose of 2500 cGy is required to completly inactivate $\mathrm{T}$ cells. Irradiation damage red cells membrane and the red cel is units can not be storage for long time after irradiation. High potassium levels is the mainly change in red cells units. White cell-reduction filters do not prevent TA-GVHD and gamma irradiation does not prevent alloimmunization or blood reactions. Oniy cellular components li ke whol e blood, red cells, pl atel ets and granulocytes need be irradiated. Ali blood components should be irradiated to: first or second-degree relatives, patients need HLA-matched platelets, recipients of allogeneic or autologous bone marrow transplantation, patients with H odgkin's disease, patients treated with purine anal ogue drugs, intrauterine transfusions, preterm infants and when congenítal immunodeficiency states is suspected. It is recomended irrradiated blood to patients with neoplastic disease when they receive intensive chemoterapy. [Rev Ass Med Brasil 1999; 45(3): 261-72.]

KEY WORDS: Graft-versus-host disease. Immunodeficiency. Transfusion and gamma irradiation. 


\section{REFERÊNCIAS BIBLIOGRÁFICAS}

1. Reiser H, Stadecker MJ . Costimulatory B7 molecules in the pathogenesis of infectious and autoimmune disease. N Engl J Med 1996; 335:1369-1377.

2. AntimJ H. Cytokines and graft-v-host disease. Prog Clin Biol Res 1994;390: 193-202

3. FerraraJ LM. Syngenic graft-vs-host disease. Arch Dermatol 1987; 123:741-742.

4. Hood AF, Vogelsang GB, Black LP et al. Acute graft-versushost disease Arch Dermatol 1987; 123:745-750.

5. Postmus PE, Muider NH, Elema J D. Graft-versus-host disease after transfusions of non-irradiated blood cells in patients having received autol ogous bone marrow. E ur J Cancer Clin Oncol 1988; 24:889-894.

6. Burdik J F, Vogelsang GB, Smith WJ et al. Severe graftversus-host disease in a liver transplant recipient. N Engl J Med 1988; 318:689-691.

7. Collins RH, Cooper B, Nikaein A et al. Graft-versus-host diseasein a liver transplant recipient. Ann I ntemai Med 1992; $116: 391-392$.

8. Hathaway WE, Githens J H, Blackburn WR et al Aplastic anemia, histiocytosis and erythrodermia in immunologically deficient children. N Engi J Med 1965; 273:953-958.

9. Przepiorka D, LeParcGF, Stovall MA et al. Use of irradiated blood components. Am J Clin Pathol 1996; 106:6-1 1.

10. J uji T, Takahashi K, Shibata $Y$ et al. Post-transfusion graftversus-host disease in immunocompetent patients after cardiac surgery in J apan. N Engl J Med 1989; 321:56.

11. Appleton AL, Sviland L, Pearson ADJ et al. Diagnostic features of transfusion-associated graft-versus-host disease. J Clín Pathol 1994, 47:541-546.

12. Takahashi K, J uji T, Miyamoto M et al. Anaiysis of risk factors for post-transfusion graft-versus-host disease in J apan. Lancet 1994: 343:700-702.

13. Anderson KC, Weinstein HJ . Transfusion-associated graftversus-host disease. N Engl J Med 1990; 323:315-321.

14. Bordin J O, Blajchman MA. Immunosuppressive effects of allogeneic blood transfusions: Implications for the patient with a malignancy. Hematologyl Oncology Clinics of North America 1995- 9:205-218

15. Brubaker DB. Transfusion-associated graft-versus-host disease. Human Pathol 1986; 17:1085-1088.

16. Thaler $M$, Shamiss A, Orgad $S$ et al. The role of blood from HLA-homozygous donors in fatal transfusion-associated graftversus-host disease after open heart surgery. N Engl J Med 1989; 321-25-28.

17. Suzuki K, Akiyama H, TakamotoS et al. Transfusion-associated graft-versus-host disease in presumably immunocompetent patient after transfusion of stored packed red cells. Transfusion 1992; 32:358-360.

18. Von Fliedner V, Higby DJ , Kim U. Graft-versus-host reaction following blood product transfusion. AmJ Med 1982; 72:951-961.

19. Capon SM, DePond WD, Tyan DB et al. Transfusion-associated graft-versus-host disease in an immunocompetent patient. Ann Intem Med 1991; 114:1025-1026.

20. Briz M, Cabrera R, Sanjuán $L$ et al. Diagnosis of transfusionassociated graft-versus-host disease by polymerasechain reaction in fludarabine treated B-chronic lymphocytíc leukaemia. Br J Haematol 1995; 91:409-411.

21. Zulian GB, Roux E, Tiercy J M et al. Transfusion-associated graft-versus-host disease in a patient treated with Cladribine (2chlorodeoxyadenosine): demonstration of exogenous DNA in various tissue extracts by PCR analysis. $\mathrm{Br} J$ Haematol 1995; 89-83-89.

22. Drobyskí W, Thibodeau S, Truitt RL et al. Third-party-mediated graft-versus-host disease after T-cell-depleted bone mar- row transplantation, as demonstrated by hypervariable DNA probes and HLA-DR polymorphism. Blood 1989; 74:2285-2294.

23. Benson K, Marks AR, Marshali MJ et al. Fatal graft-versushost disease associated wíth transfusions of HLA-matched, HLA-homozygous platelets from unrelated donors. Transfusion 1994; 34:432-437.

24. Decoste SD, Boudreaux C, Dover J S. Transfusion-associated graft-versus-host disease in patients with malignancies. Arch Dermatol 1990; 126:1324-1329.

25. Parkman R, Moiser D, U manskyL etal. Graft-versus-host disease after intrauterineand exchangetransfusion for hemolytic disease of the newborn. N Engl J Med 1974; 290:359-363.

26. Shivdasani RA, Haluska FG, Dock NL et al. Brief report: graft-versus-host diseaseassociated with transfusion of blood from unrelated HLA homozygous donors. N Engl J Med 1993; 328:766-770.

27. Akahoshi M, Takanashi M, Masuda M et al . A case of transfusion associated graft-versus-host disease not prevented by white cell-reduction filtors. Transfusion 1992; 32-169-172.

28. Spitzer TR, Cahill R, Cottier-F ox M et al. Transfusion-induced graft-versus-host disease in patients with malignant lymphoma Cancer 1990; 66:2346-2349.

29. Blundell EL, Pamphilon DH, Anderson NA et al. Transfusion associated graft-versus-host disease, monoclonal gammopathy and PCR. Br J Haematol 1992; 82:622-623.

30. KennedyJ S, Ricketts RR. Fatal graft v host disease in a child with neuroblastoma following a blood transfusion. J Pediatr Surg 1986; 21:11081109.

31. Yasukawa M, Shinozaki F, HatoT et al. Successful treatment of transfusion-associated graft-versus-host disease. $\mathrm{Br}$ J Haematol 1994; 86:831 836.

32. Otero AG, Del Rio MV, Svarch EG et al. Enfermedad injerto contra husped despues de la transfusion de granulocitos. Comunicacion de un paciente. Rev Cubana Hematol Imunol Hemoter 1989; 5:456-61.

33. Held J L, Druker BJ , Kohn SR et al. Atypical, nonfatal, transfusion associated acutegraft-versus-host diseasein a patient with Hodgkin's disease. J Am Acad Dermatol 1992 -1 26:261-262.

34. Van Der Mast BJ , Hornstra N, Rulgrok MB et al. Transfusion associated graft-versus-host disease in immunocompetent patients. Self protective mechanism. Lancet 1994; 343:753-757.

35. Otsuka S, Kunieda K, Hirose M et al. Fatal erythroderma (suspected graft-versus-host disease) after cholecystectomy. Transfusion 1989; 29:544-548.

36. Naiman J L, Punnett HH, Lischner HW et al. Possible graftversus-host reaction after intrauterine transfusion for $\mathrm{Rh}$ erythroblastosis fetalis. N Engl J Med 1969; 281:697-701.

37. Woods WG, Lubin BH. Fatal graft versus host disease following a blood transfusion in a child with neuroblastoma. Pediatrics 1981; 67:217-221.

38. Arsura EL, Bertelle A, Minkowitz $\mathrm{S}$ et al. Transfusion-associated graft-versus-host disease in a presumed immunocompetent patient. Arch Intem Med 1988; 148: 1941-1944.

39. O'Connor NTJ, Mackintosh P. Transfusion associated graft versus host disease in an immunocompetent patient. J Clin Pathol 1992; 45:621-622.

40. Marcus] N, HLA-homozygous donors and transfusion-asociated graft-versus-host disease. N Engl J Med 1990- 322-1004-1005.

41. Perkins HA. Should all blood from related donors beirradiated? Transfusion 1992; 32:302-303.

42. Lee $\mathrm{T}-\mathrm{H}$, Donegan $\mathrm{E}$, Slichter $\mathrm{S}$ et al. Transiet increase in circulating donor leukocytes after allogeneic transfusions in immunocompetent recipients compatible with donor cell proliferation. Blood 1995; 85-.1207-1214.

43. Wakayashi $T$, Onoda $H$, Kirita $Y$ et al. Distribution of the dendritic cell in human organs and incidence of GHVD. Transpl Proc 1997; 29:737-738. 
44. Ferrara J LM, Deeg HJ . Graft-versus-host disease. N Engi J Med 1991; 324:667-674.

45. Kobayashi E, Enosawa S, Toyama $\mathrm{N}$ et al. Surgical damage itself induces graft-versus-host disease- A preliminary report. Transpl Proc 1996-, 28:3652-3653.

46. FerraraJ LM, CookeKR, Pan L etal. Theimmunopathophysiology of acute graft-versus-host disease. Stem Cells 1996; 14:473-489.

47. Sherman L, Menitove J Kagen LR etal. Ultraviolet-B irradiation of platelets: a preliminary trial of efficacy. Transfusion 1992; 32:402-407.

48. Dzik WH, J ones KS. The effects of gamma irradiation versus white cell reduction on the mixed lymphocyte reaction. Transfusion 1993; 33:493-496.

49. Wieding J U, Vehmeyer K, Dittman J et al. Contamination of fresh-frozen plasma with viable whíte cells and proliferable stem cells. Transfusion 1994; 34:185-186.

50. Rosen NR, Weidner J G, Boldt HD et al. Prevention of transfusion associated graft-versus-host disease: selection of an adequate dose of gamma radiaton. Transfusion 1993- 33-125-127.

51. Pelszynski MM, M oroff G, Luban NLC et al. Effect of ( irradiation of red blood cell units on T-cell inactivation as assessed by limiting dilution analysis: Implications for preventingtransfusion-associated graft-versus-host disease. Blood 1994; 83:1683-1689.

52. Hillyer CD, Tiegerman KO, Berkman EM. Evaluation of the red cell storage lesion after irradiation in filtered packed red cell units. Transfusion 1991; 31:497-499.

53. Davey RJ , McCoy NC, Yu M et al. The effect of prestorage irradiation on posttransfusion red cell survival. Transfusíon 1992; 32:525-528.

54. Ramirez AM, Woodfield DG, Scott R et al. High potassium levels in stored irradiated blood. Transfusion 1987- 27-444-445.

55. Rivet C, Baxter A, Rock G. Potassium levels in irradiated blood. Transfusion 1989; 29:185-186.

56. Read EJ , Kodis C, Carter CS etal. Viability of platel ets following stored in the irradiated state. Transfusion 1988; 28:446-450.
57. Kanter MH. Transfusion-associated graft-versus-host disease: do transfusions from second-degree relatives pose a greater risk than those from first-degree relatives ? Transfusion 1992- 32-.323-327.

58. Ohto $H$, Yasuda $H$, Noguchi $M$ et al. Risk of transfusionassociated graft-versus-host disease as a result of directed donations from relatives. Transfusion 1992; 32:691-693.

59. Charpentier F, Bracq C, Bonin P et al. HLA-matched blood products and posttransfusion graft-versus-host disease. Transfusion 1990, 30:850.

60. Blood Transfusion Task F orce. Guidelines on gamma irradiation of blood components for the prevention of transfusion asoociated graft versus host disease. Transf Med 1996; 63:261-271.

61. Mulder NH, Elema J D, Postmus PE. Transfusion associated graft-versus-host disease in autologous bone marrow transplantation. Lancet 1989; 1(8640):735-736.

62. Twomey J J , Rice L. Impact of Hodgkin's disease upon the immune system. Semin Oncol 1980- 7.-114-125.

63. Dighiero G, Binet J L. Chronic lymphocytic leukemia. Hematol Cell Ther 1996; 38: S41-S61.

64. Maung ZT, Wood AC, J ackson GH etal. Transfusion-associated graft-versus-host disease in fludarabine-treated B-chronic Iymphocytic leukemia. Br J Haematol 1994; 88:649-652.

65. Hayakawa S, Chishima F, Sakata $\mathrm{H}$ et al. A rapid molecular diagnosis of postransfusion graft-versus-host disease by polymerase chain reaction. Transfusion 1993- 33-413-417.

66. Drut R, Drut RM. Enfermedad injerto contra huesped asociada a transfusiones. Reconocimiento de dos casos infantes por I a biopsia de piel. Medicina 1989; 49:603-606.

67. Kessinger A, Armitage J O, Klassen IW et al. Graft versus host disease following transfusion of normal blood products to patients with malignancies. J Surg Oncol 1987; 36-206-209. 